\title{
Nanostructured Ruthenium Disulfide Catalyst High Active in the HDS of DBT
}

\author{
C. Ornelas ${ }^{1 *}$, C. Leyva-Porras ${ }^{2}$, D. Carrillo ${ }^{3}$, A. Aguilar-Elguézabal ${ }^{1}$ and L. Alvarez-Contreras ${ }^{1}$
}

${ }^{1}$ Centro de Investigación en Materiales Avanzados (CIMAV), Laboratorio Nacional de Nanotecnología, Miguel de Cervantes No.120, C.P. 31109, Chihuahua, Chih., México

${ }^{2}$ Centro de Investigación en Materiales Avanzados, S.C. (CIMAV); Alianza Norte No. 202, Parque de Investigación e Innovación Tecnológica (PIIT), C. Aeropuerto km. 10 Apodaca, N.L. México. C.P. 66600

${ }^{3}$ Institute of Engineering and Technology, Autonomous University of Juarez, UACJ, Ave. del Charro \#610 norte, C.P. 32320, Cd. Juárez, Chihuahua, México

Recently our research group achieves to develop a way to synthesized very high catalytic activity RuS $\mathrm{S}_{2}$ catalysts, for the hidrodesulfuration (HDS) of dibenzothiofene (DBT) process [1, 2], in agreement to predicted in the past years by different groups $[3,4,5,6]$. Low sulfurations levels was related with the low catalytic activity in the ruthenium sulfide catalyst due to remaining of metallic ruthenium in the catalyst, this poor sulfuration was associated with hydrogen used during the activation process which is a high reducing agent $[7,8,9]$, nevertheless our group achieved excellent catalytic activity with very high reduction atmosphere of $98 \% \mathrm{H}_{2} / \mathrm{H}_{2} \mathrm{~S}$ [10] this means that different characteristics are responsible of high activity in the catalyst for HDS reaction.

Nanoestructured $\mathrm{RuS}_{2}$ catalyst was synthesized according to previous work $[9,10]$ and characterized by electron microscopy, this nanoestructured catalyst has especial interest because it's high activity in the HDS of DBT process many times better than industrial catalysts. The catalyst was synthesized following the procedure used in previous work $[9,10]$ and was activated by $2 \mathrm{hr}$ in a tubular furnace at $673 \mathrm{~K}$ whit reduction atmosphere of H2S. The resulted catalysts were tested in the HDS of DBT reaction. The HDS studies were carried out in a Parr model 4560 high-pressure batch reactor. 0.25 gram of catalyst was placed in the reactor with a solution of $5 \mathrm{vol}$. \% of DBT in decaline. The reactor was pressurized to 3.1 MPa with hydrogen and heated up until $623 \mathrm{~K}$. After the working temperature was reached, sampling for chromatographic analysis was performed during the course of each run to determine conversion versus time dependence.

Electron Microscopy HRTEM JEOL JEM2200FS+Cs and SEM JEOL JSM-7001F were used to characterize the catalyst, micrographs obtained by SEM (fig 1a) ) show a porous structure of ruthenium sulfide with some excess of sulfur $(\mathrm{S} / \mathrm{Ru}$ ratio $=3.1)$, that means that the sulfidation process was good enough to make complete sulfidation of all the ruthenium atoms, diffraction patterns obtained by HRTEM show ruthenium sulfide as pyrite type crystalline structure $\left(\mathrm{RuS}_{2}\right)$, the morphology of the obtained catalyst is small crystals agglomerated and sinterized type sheets made of nanocrystals between 2 and 10 nanometers principally less than 5 nanometers with very high porosity between the particles and other sheets, the figure $1 \mathrm{~b}$ ) to d) show clearly this morphology. The use of pure H2S gas flow in the sulfidation process allows to synthesized nanostructured RuS2 catalysts with a lot high active sites for the HDS of DBT reaction responsible of the good catalytic activity. 
References:

[1] Ornelas Gutiérrez Carlos Elías, et al. Mexican patent MX/a/2011/013529

[2] Ornelas Gutiérrez Carlos Elías, et al. US Patent 13/444,411.

[3] Pecoraro T. A. and Chianelli R. R., Journal of Catalysis, 67 Issue 2 (1981), 430-445.

[4] Raje A. P, et al, Applied Catalysis A: General 150 (1997), 297-318.

[5] Liaw S-J., et al, Applied Catalysis A: General 151 (1997), 423-435.

[6] Chianelli R. R., Berhault G., Torres B., Catalysis Today, 147, (2009) 275-286.

[7] Navarro R., et al, 1999. Fuel Processing Technology, 61, pp. 73-88.

[8] Castillo-Villalon P., et al, 2008. Journal of Catalysis, 260, pp. 65-74.

[9] Blanchard J., et al, 2009. Catalysis Today, 147, pp. 255-259

[10] Ornelas C., et al, 2014. Microsc. Microanal. 20 (Suppl 3), 2014 pp. 1980-1981

Presenting author's email: e-mail address * carlos.ornelas@cimav.edu.mx
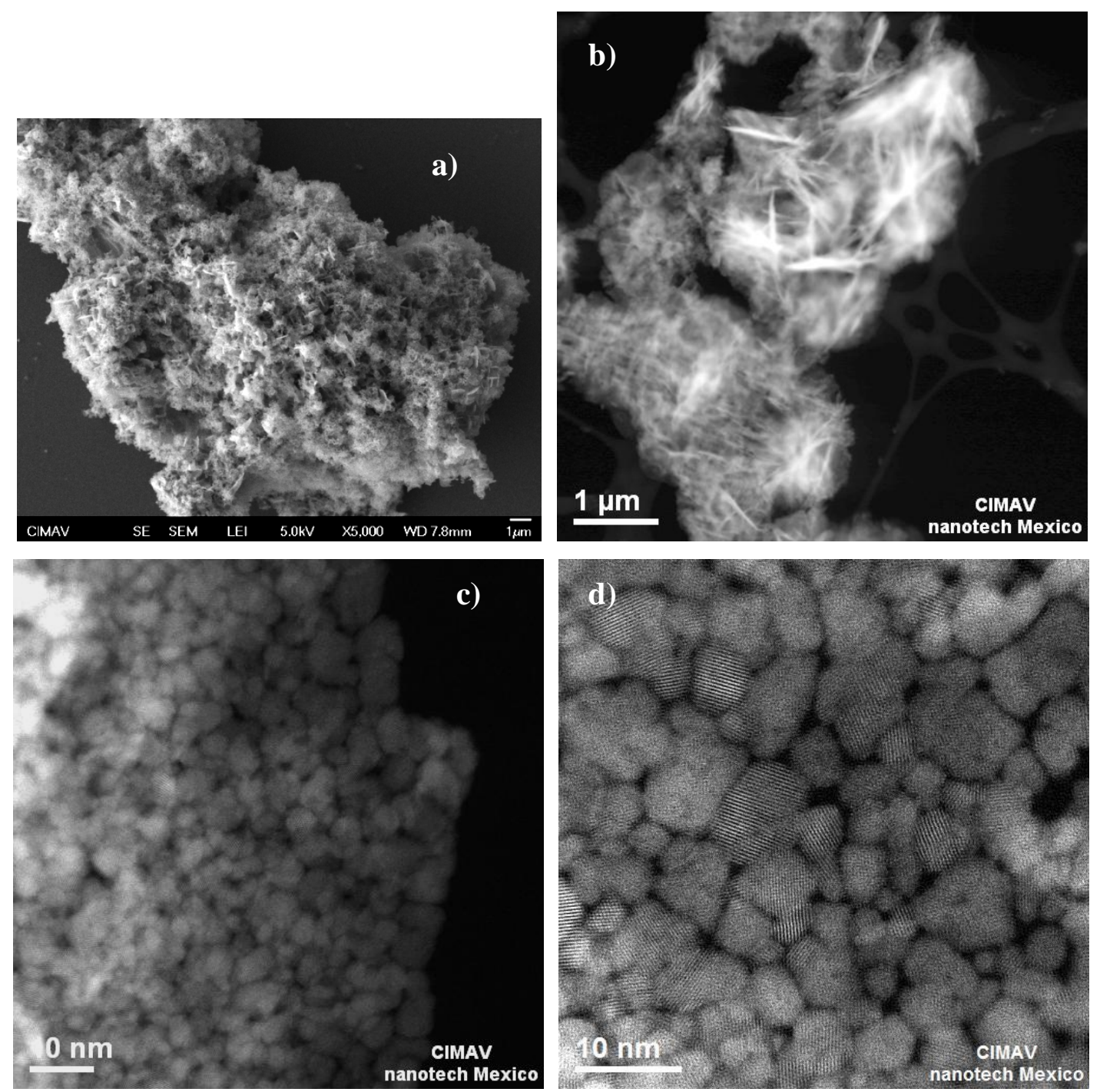

Figure 1. RuS 2 Catalysts, (a))SE SEM Image, (b)-d) $\mathrm{Z}$ contrast micrographs by HRTEM of catalyst. 